\title{
AVALIAÇÃO DE FONTES DE INFORMAÇÃO NA INTERNET
}

TOMAÉL, Maria Inês; VALENTIM, Marta Lígia Pomim. (Orgs). Avaliação de fontes de informação na internet. Londrina:

EDUEL, 2004. 155p.
É indiscutível a vertiginosa evolução da tecnologia de informação, principalmente nas duas últimas décadas; por conseqüência, a internet tornou-se uma excelente fonte de consulta. Contudo, na maioria das vezes, os dados contidos na rede não estão disponibilizados e estruturados de forma que o usuário consiga recuperá-los e transformá-los em informações úteis de acordo com suas necessidades.

O livro intitulado "Avaliação de Fontes de Informação na Internet", organizado pelas docentes: Maria Inês Tomaél e Marta Lígia Pomim Valentim, apresenta os avanços, tanto das novas tecnologias, como das telecomunicações. Avanços estes que possibilitaram a expansão da comunicação e a transferência de documentos e conhe- cimentos, culminando na exorbitante geração e produção de novas informações.

Estas idéias estão presentes no decorrer dos capítulos do livro, desde a introdução aos subseqüentes sete capítulos que compõem a obra, relatando, em formato acadêmico e em linguagem clara, a evolução das tecnologias de informação, além de formas de organização e de recuperação de informações contidas na internet.

Inicialmente, apresenta a evolução e a importância das mídias como ferramenta de trabalho nas organizações, sejam elas acadêmicas ou empresarias; o livro alerta para o auxílio que estas tecnologias têm proporcionado na automação e transmissão de informação nas diversas áreas de pesquisa. 
O primeiro capítulo aponta a necessidade de "filtros" para recuperação de informação com qualidade, conforme a seletividade do perfil de interesse específico. Analisa padrões de qualidade que auxiliam na avaliação de fontes de informação da internet, relacionando critérios e atributos de avaliação como: validade, precisão, autoridade, reputação da fonte, singularidade, completeza e cobertura, integridade da informação e do site consultado.

A informação atualizada assume, cada vez mais, importante papel, tornando-se imprescindível para crescimento e/ou sobrevivência de organizações e de profissionais. Desta forma, nas últimas décadas, houve notável crescimento de fontes eletrônicas. O texto Identificação Análise e Seleção de Dicionários e Enciclopédias na Internet, no segundo capítulo, identifica mecanismos de recuperação de informações contidas em dicionários e enciclopédias nacionais disponíveis na Internet. Define tais fontes e analisa as formas de acesso, considerando a limitação de uso de recursos como links, e sistema de ajuda (help), o que de certa forma limita a relevância da informação recuperada.

O terceiro capítulo trata dos Portais Verticais, descrevendo-os como a "evolução" das chamadas home-pages, como eram denominados os primeiros sites. Estes portais oferecem serviços e acesso a uma crescente quantidade de informações, serviços e comércio de produtos na internet. Devido à necessidade de informação especializada, os portais verticais evoluíram substancialmente em número e qualidade, proporcionando aos usuários valores agregados como serviços de chats, listas de discussões, que possibilitaram a formação de comunidades virtuais, criação de emails gratuitos, entre outras vantagens, de valor comercial ou acadêmico.

Apontadores como Fontes de Informação é o titulo do quarto capítulo. Estes "apontadores" são definidos como links agrupados sistematicamente em categorias que reportam a outros sites com conteúdos afins, de forma a agilizar a localização e/ou complementar a informação. O cuidado que deve ser tomado para analisar a qualidade com os apontadores (links) é o mesmo com relação aos sites, ou seja, verificar a veracidade e, principalmente, a atualização.

O quinto capítulo trata das Fontes de Informação Industrial na Internet, descritas como mecanismos de auxílio na recuperação da informação para essa categoria empresarial. Define a informação como instrumento indispensável e recurso básico de auxílio ao crescimento da produção de uma organização, sendo imprescindível para o desenvolvimento da competitividade, analisando a informação contida nas fontes disponíveis na internet, a falta de 
organização e deficiências nos mecanismos de recuperação dos dados.

Fontes de informação na Internet: software para unidades de informação é o assunto discorrido no sexto capítulo. O texto aponta ferramentas básicas que auxiliam, identificam, analisam e selecionam fontes a respeito de softwares internacionais para unidades de informação como: bibliotecas, arquivos e museus. Os critérios adotados para esta análise incluem: atualidade, confiabilidade, adequação de links para informações complementares, facilidade de uso e o layout das fontes. Constata-se que a internet otimiza sobremaneira a ação de avaliação de softwares pois os gestores de automação podem ter acesso a quantidade maior de informações, melhorando a qualidade na tomada de decisão.

O último capítulo, denominado: Fontes de Informação Pública na Internet, discute fontes nacionais de comunicação e informação, que agregam a oportunidade de socialização da informação, pois contribuem para a produção e a difusão de novos conhecimentos que podem auxiliar no meio acadêmico e na sociedade em geral. Foram identificadas, analisadas, avaliadas e selecionadas fontes de informação da área pública, como: sites de biblioteca, museus, arquivos, centros culturais. Verifica-se grande fragilidade na veiculação de informações de caráter público ou direcionadas para a cidadania.
De modo geral, a falta de organização na disponibilização das informações e a insipiência de mecanismos de recuperação que atendam a um perfil de interesse, têm prejudicado o resgate da informação na internet. A evolução das tecnologias proporcionou maior acesso à informação, contudo, há de se atentar para a grande quantidade de informação sem relevância; cabe então, principalmente ao profissional da informação, criar e fazer uso de critérios e estratégias específicas para que a informação recuperada possa suprir as reais necessidades informacionais da pessoa e/ou organização. A obra "Avaliação de Fontes de Informação na Internet", em cada um de seus capítulos, traz vários exemplos e sugestões que podem ser de grande auxílio neste sentido.

\section{Selma Alice Ferreira Ellwein}

Especialista em Gerência de Unidades de Informação - UEL

ellwein@sercomtel.com.br

\section{Title}

Evaluation of information sources on the Internet

\section{Título}

Evaluación de fuentes de información en Internet 